Article

\title{
Expected Changes to Alpine Pastures in Extent and Composition under Future Climate Conditions
}

\author{
Camilla Dibari ${ }^{1}{ }^{(}$, Sergi Costafreda-Aumedes ${ }^{1, *} \mathbb{C}$, Giovanni Argenti ${ }^{1}\left(\mathbb{C}\right.$, Marco Bindi ${ }^{1}(\mathbb{C}$, \\ Federico Carotenuto ${ }^{2}$, Marco Moriondo ${ }^{2}$ (D), Gloria Padovan ${ }^{1}$, Andrea Pardini ${ }^{1}$, \\ Nicolina Staglianò ${ }^{1}$, Carolina Vagnoli ${ }^{2}$ (D) and Lorenzo Brilli ${ }^{2}$ (I) \\ 1 Department of Agriculture, Food, Environment and Forestry (DAGRI), University of Florence, Piazzale delle \\ Cascine 18, 50144 Florence, Italy; camilla.dibari@unifi.it (C.D.); giovanni.argenti@unifi.it (G.A.); \\ marco.bindi@unifi.it (M.B.); gloria.padovan@unifi.it (G.P.); andrea.pardini@unifi.it (A.P.); \\ nicolina.stagliano@unifi.it (N.S.) \\ 2 CNR-IBE, via Madonna del Piano 10, 50019 Florence, Italy; federico.carotenuto@ibe.cnr.it (F.C.); \\ marco.moriondo@cnr.it (M.M.); carolina.vagnoli@ibe.cnr.it (C.V.); lorenzo.brilli@ibe.cnr.it (L.B.) \\ * Correspondence: sergi.costafredaaumedes@unifi.it; Tel.: +39-055-255742
}

Received: 21 April 2020; Accepted: 16 June 2020; Published: 28 June 2020

check for updates

\begin{abstract}
As the basis of livestock feeding and related performances, pastures evolution and dynamics need to be carefully monitored and assessed, particularly in the Alps where the effects of land abandonment are further amplified by climate change. As such, increases in temperature associated with changes in precipitation patterns and quantity are leading to modifications of grassland extent and composition with consequences on the pastoral systems. This study applied a machine learning approach (Random Forest) and GIS techniques to map the suitability of seven pasture macro types most representative of the Italian Alps and simulated the impact of climate change on their dynamics according to two future scenarios (RCP4.5, 8.5), two time-slices (2011-2040, 2041-2070), and three RCMs (Aladin, CMCC, ICTP). Results indicated that (i) the methodology was robust to map the current suitability of pasture macro types (mean accuracy classification $=98.7 \%$ ), so as to predict the expected alterations due to climate change; (ii) future climate will likely reduce current extend of suitable pasture ( $-30 \%$ on average) and composition, especially for most niche ecosystems (i.e., pastures dominated by Carex firma and Festuca gr. Rubra); (iii) areas suited to hardier but less palatable pastures (i.e., dominated by Nardus stricta and xeric species) will expand over the Alps in the near future. These impacts will likely determine risks for biodiversity loss and decreases of pastoral values for livestock feeding, both pivotal aspects for maintaining the viability and profitability of the Alpine pastoral system as a whole.
\end{abstract}

Keywords: alpine pasturelands; climate change; grasslands composition; Random Forest; modeling

\section{Introduction}

The Alpine chain is about $1200 \mathrm{~km}$ long and $200 \mathrm{~km}$ wide, stretching across eight European countries (i.e., Austria, France, Germany, Italy, Switzerland, Liechtenstein, Slovenia, and Monaco). The location of the Alps (frontal system crossing Europe in a west-east direction), beside the wide variation in exposure, elevation, and its arc-like shape determine a unique climate which also depends on local differences and position of reliefs [1]. This in turn determines the presence of a large variety of habitats and species. Within the whole area, grasslands and pastures represent about $25 \%$ of the Alpine vegetation, most of them semi-natural after centuries of human activities [2]. Beside production, these ecosystems are widely recognized as providing several socio-economic services for people living both in mountains and urban areas [3-5]. These include cultural services such as recreation and tourism; 
provisional services such as material or energy outputs and local products (e.g., food); environmental services such as greenhouse gas mitigation and some specific regulating services such as the prevention of fire risks $[6,7]$.

In the context of socio-economic services, livestock activities still play a crucial role especially for smallholder farmers, breeders, agronomists, and shepherds mainly due to the marketing of dairy and other animal products resulting in cash and in-kind incomes $[8,9]$. As a result, the pastures, being the basis for livestock activity and the related performances, need to be thoroughly monitored and assessed, taking into account that livestock management and stocking rate can affect pasture types occurrence and distribution [10]. Pasture biomass and the related quality of forage produced, indeed, strongly influence animal welfare and their final production [11-13]. Therefore, a change in pastures' botanical composition, production, and quality can affect the final production, with important socio-economic consequences for these rural areas. In the past decades, mountain areas experienced remarkable socio-economic changes (such as land abandonment, reduction of agricultural practices, ageing of farmers, urbanization, etc.,) determining a degradation of pastoral systems, invasion of unpalatable grasses, shrubs encroachment and reforestation [14]. Even if these trends are ongoing, nowadays slightly less than 3 million of inhabitants (roughly 14\% of the local population) live and derive their livelihoods in inner areas of Alpine regions [15].

Nowadays, the already high complexity in the understanding of the changes to pastures dynamics in terms of size and composition with the related repercussions on the livestock sector because of aspects such as agricultural land abandonment and land-use policies [16,17], is further exacerbated by the current climate change. An average increase of $0.8^{\circ} \mathrm{C}$ has been recorded across the European Alps at high elevation stations in the period 1981-2010 [18] and for the future an increase ranging between 1 and $2{ }^{\circ} \mathrm{C}$ is expected [19]. Precipitations show a more uncertain pattern, but all the studies agree to a remarkable reduction in summer [20]. Natural pastures, i.e., grasslands managed by livestock grazing, located in the Alpine mountain range are indeed widely acknowledged to be very sensitive and vulnerable to climate conditions [21-24]. Therefore, the expected increase in temperature associated with changes in precipitation pattern and quantity may lead to changes in the extent and composition of Alpine pastures, resulting in a reduction and/or losses of specific macro-types and plant species with consequences also on forage quality and management practices $[22,23,25,26]$. As a result of the general predicted warming, an altitudinal shift is expected on the basis of many studies conducted on mountain vegetation. Pauli et al. [27] highlighted in a study that involved 17 ranges all over Europe, the increase of more warm tolerant species with respect to cold tolerant and a generalized upward shift of vegetation species in the future. Other studies, assessing the main climate change foreseen effects on grasslands provided evidence of other ecological consequences, such as a reduction in suitable grassland areas, increasing in xeric species, enhancement of shrubs encroachment (e.g., [26,28,29]). Providing information on the expected changes in the presence and composition of natural grasslands would be useful for understanding and tackling the future risks to those Alpine regions where the livestock sector still plays a key role for mountain society. To our knowledge, a comprehensive assessment of climate change impacts on the Italian Alpine pasturelands and their evolution on a large-scale basis is still lacking.

To fill this gap, in this study we applied a machine learning approach integrated with spatial data through GIS techniques in order to spatially define and environmentally characterize the main pasture macro-types over the Italian Alps and their expected changes in extent and composition according to future climate conditions. Specifically, a Random Forest model (RF) was used to predict future change in macro-types on the Alpine chain under two future representative concentration pathway scenarios-RCPs (RCP4.5 and RCP8.5, as established by the AR5 IPCC report [30]), two time-slices (2011-2040 and 2041-2070) and three Regional Circulation Models-RCM (Aladin, CMCC, ICTP). 


\section{Materials and Methods}

\subsection{Study Area}

The study area, extending about 5.4 million ha across the Italian Alpine chain, in a range between $43^{\circ}$ and $47^{\circ}$ Lat north and $6^{\circ}$ to $14^{\circ}$ Lon east at an altitude higher than $1000 \mathrm{~m}$ above sea level [31], shows a complex spatial terrain pattern reflecting a "continental temperate cold climate" [32], characterized by a relevant spatial variability of both air temperature and rainfall [33]. Climatic conditions are closely related to continentality, altitude, and latitude [34], and can vary dramatically within short distances [33]. The highest amount of precipitations is recorded along the north-eastern and western Alps (1.500-2.700 $\mathrm{mm} /$ year), while lower amounts (500 to $950 \mathrm{~mm} /$ year) fall on the central and south-western Alps. At an altitude of about $2000 \mathrm{~m}$, snow cover lasts approximately from mid-November to the end of May. In such a wide and heterogeneous area, geological substrata are very diverse [35]: pedology is extremely complex and different soils can be found, ranging from siliceous to different types of calcareous of sedimentary origin [10].

The study area is dominated by different plant communities, mainly forests and herbaceous vegetation [36]. The presence and productivity capacity of grasslands is strongly dependent on topsoil $\mathrm{pH}$ and climate conditions [37], but is also affected by management and livestock grazing [38].

\subsection{Methodology}

The methodology applied in this study combines the use of pre-existent environmental (topography, soil) and climate spatial layers as drivers of the distribution of the main pasture macro-types dominating the region, without considering the influence of human activity. Specifically, these spatial layers were used as predictor variables of occurrence of different macro-types by using a machine learning approach (Breiman and Cutler's Random Forests for Classification and Regression-RF, [39]). RF was first calibrated and validated for the present period, so as to test its ability to faithfully predict the to-date spatial distribution of both pasturelands and the relevant macro-types. The calibrated RF was then applied to reproduce the dynamics of pasture macro-types distribution over the Italian Alps region according to RCP 4.5 and 8.5, using three regional circulation models (RCMs) for two future time-slices (2011-2040, 2041-2070). The calibration and validation strategy of RF model is described as well as the ensemble approach used to synthesize the outputs for future periods obtained from three RCMs. In the following sections, a brief description of the spatial dataset used is reported, along with the relevant spatial scales and harmonization procedures adopted.

\subsubsection{Predictor Variables: Topographic, Soil, and Climate Dataset}

The complexity in estimating current pasture macro-types and their evolution under future climate conditions over the study area was addressed by integrating pre-existing datasets on pasture vegetation with spatial information on soil, topography, and climate. Elevation, slope, and $\mathrm{pH}$ were extracted from the Harmonized World Soil Database-HWSD [40], while monthly climate data (Tmin, Tmax, and cumulated rainfall) were provided by the WorldClim database [41] for 1970-2000 as baseline. All these datasets were available at the same spatial resolution, approximately $1 \times 1 \mathrm{~km}$ (see [42] for further details).

The outputs of three regional circulation models (RCMs) were empirically downscaled using a delta change approach over the WorldClim gridded baseline climate (1970-2000) to provide informative layers for RF application in RCP4.5 and RCP8.5 future scenarios. Specifically, monthly minimum and maximum temperature (Tmin and $\operatorname{Tmax},{ }^{\circ} \mathrm{C}$ ), and cumulated rainfall (Rain, mm), as simulated by CNRM-ALADIN (spatial resolution $\left.0.11^{\circ} \times 0.11^{\circ}\right)$, ICTP-RGCM4 $\left(0.44^{\circ} \times 0.44^{\circ}\right)$, and CMCC-CCLM4 $\left(0.44^{\circ} \times 0.44^{\circ}\right)$ from MedCordex [43], were averaged on a monthly basis for the relevant reference period 1970-2000 and for two time-slices: 2011-2040 and 2041-2070 for RCP4.5 and 8.5 scenarios. The absolute monthly differences between each future time-slice and the reference period computed for Tmin and Tmax was then overlaid over the relevant months of the WorldClim dataset. The same 
approach was used for rainfall, where the change was expressed as the ratio between each future time-slice and the reference period. The final climatic dataset consisted of twelve combinations of Tmin in January, Tmax in July, and seasonal rainfall calculated for three RCMs (CNRM-ALADIN, ICTP-RGCM4, CMCC-CCLM4) two-time slices (2011-2040 and 2041-2070, two RCPs (RCP4.5 and 8.5).

\subsubsection{Response Variables: Pasturelands and Pasture Macro-Types Dataset}

Current distribution of pasturelands was extracted from corresponding codes of the CORINE Land cover (https://land.copernicus.eu), namely code 321 (Natural Grasslands), code 322 (Moors and Heathland), and code 324 (Sclerophyllous vegetation); while, information on pasture composition was retrieved aggregating pastoral maps, available for only some areas only of the Italian Alpine mountain range [44,45], with the habitat map named Carta della Natura (CDN; [46]). The reference of the corresponding CORINE Biotopes classification code [47] was used to harmonize a comprehensive legend of seven macro-types characterizing the Italian Alps, named according to Pignatti [48] as: (i) pastures encroached by shrub species (SP) (mainly by Chamaephytes sensu Raunkiaer, [49]); (ii) pastures dominated by Carex curvula (CC); (iii) pastures dominated by Carex firma (CF); (iv) pastures dominated by Nardus stricta (NS); (v) pastures dominated by Festuca gr. rubra (FR); (vi) pastures dominated by Sesleria varia (SV); and (vii) pastures dominated by xeric species (XS) (see [31] for further details).

Both datasets (the unclassified pasturelands and seven macro-types) were converted into two grid datasets, spatially consistent with the predictor variables dataset $(1 \times 1 \mathrm{~km}$ spatial resolution, EPSG: 4326). Specifically, we created one dataset related to the overall distribution of pasturelands (1), and a second one related to the distribution of the seven pasture macro-types (2). The first (1), presence/absence of pasturelands, was determined by aggregating those pixels classified as pastures in the CORINE land cover map with those in which at least one macro-type occurred (presence of pasturelands). Other land uses, potentially suited to the seven pasture macro-types, such as agricultural and forested areas (Class 2 and Class 3 of level 1 of CORINE land cover map, respectively) and wetlands (Class 4 level 1), were also incorporated into the spatial dataset as "absence" response variable. The second dataset (2), macro-type dataset, was created by calculating the coverage of each pasture macro-types within the same $1 \times 1 \mathrm{~km}$ grid cell. The presence of each macro-type was counted when covering at least $10 \%$ of the total area within each $1 \times 1 \mathrm{~km}$ pixel, assigning the most prevalent macro-type (in terms of coverage) to each pixel.

Finally, both datasets, i.e., pasturelands (1) and pasture macro-type (2) were harmonized with the predictor variables dataset (topography, soil and climate) into a coherent comprehensive dataset (49,405 pixels in total), including: (i) the predictive abiotic independent variables (eight in total); (ii) the presence of pasture macro-types (seven response variables); (iii) the presence/absence of unclassified pasturelands; and (iv) the presence/absence of other land uses. The final dataset comprised 19,748 pixels of actual occurrence of pastoral resources, namely 8866 of unclassified pasturelands, 10,882 of classified pastures (pasture macro-types), and 29,657 of other land use (Table 1).

Table 1. Number of pixels (100 ha wide each) observed for each macro-types, unclassified pasturelands and other land uses of the training dataset (response variables).

\begin{tabular}{cc}
\hline Legend & Number of Pixels \\
\hline SP: pastures encroached by shrub species & 4101 \\
CC: pastures dominated by Carex curvula & 2661 \\
CF: pastures dominated by Carex firma & 1185 \\
NS: pastures dominated by Nardus stricta & 5030 \\
FR: pastures dominated by Festuca gr. rubra & 503 \\
SV: pastures dominated by Sesleria varia & 3560 \\
XS: pastures dominated by xeric species & 1560 \\
Un-classified pastures & 8866 \\
Other land use & 29,657 \\
\hline
\end{tabular}




\subsubsection{Random Forest: Model Set Up, Calibration, and Validation}

Occurrence probabilities for unclassified pasturelands and seven pastoral macro-types was modeled using the Random Forest (RF) machine learning algorithm [39], as implemented in $\mathrm{R}$ environment (package "randomForest"). RF is a classification and regression ensemble of decision trees classifiers, commonly used in studies on species distribution and changes analysis [42,50-53], acknowledged as giving the most accurate performances in predicting species distributions using a large set of independent variables [54-56] also over unbalanced datasets [39]. RF is able to make internal cross-validated accuracy estimates, as each classifier is generated by a bootstrap sample randomly divided into an internal training (66\% of data) and testing subset (33\% out-of-bag sample, $\mathrm{OOB}$ error), thus giving cross-internal classification error estimates. RF predictions are made giving a majority vote to the ensemble of classification trees and the final model prediction is generated taking the most voted model over all the trees generated within the forest. The response variable of RF is binary, i.e., presence (1) and absence (0), and the model provides, as output, the probability scores from model application. Additionally, RF provides, as final product from the calibration mode, the mean decrease accuracy, which puts in evidence the relative importance of each predicting variable of the model in distinguishing macro-types in the calibration phase, as well as the marginal effect of each variable on model prediction (partial dependence plots).

The predictive independent abiotic variables comprised: $\mathrm{pH}$, altitude $(\mathrm{m})$, slope $(\%)$, monthly average maximum temperature of July $\left({ }^{\circ} \mathrm{C}\right.$, Tmax_jul), monthly average minimum temperature of January $\left({ }^{\circ} \mathrm{C}, \mathrm{Tmin} \_\right.$jan$)$, as proxy of extreme environmental factors (e.g., [57]) and cumulated seasonal precipitation (mm, Prec_djf,Prec_jja, Prec_mam, and Prec_son), relevant to characterize the seven macro-types across the study area [31].

As RF predictions might be biased by unbalanced datasets (proportion between presence and absence classes), likely resulting in over-prediction of the majority-class, a multi-step strategy for RF calibration was adopted. First, the extent of pasturelands was determined by coupling the geographical extent of all macro-types [31] with the unclassified pastures (Corine land cover map) for training RF. Second, within the area identified by RF as suitable for pasturelands at this stage, the most suited macro-type was determined on a pixel-by-pixel basis. Finally, ten sub-sampling datasets were randomly down-sampled from both datasets (pasturelands and macro-type dataset), so as to have a proportion of the majority class (presence of pastureland and/or macro-type) consistent (i.e., with the same number of occurrences) with the minority-class (other land uses) to be used for RF calibration.

Separately, for each unclassified pastureland and seven pasture macro-types dataset, the ten random sub-samples of RF models were then combined into a final model and thus applied over both datasets against abiotic independent variables and current climate. The mtry parameter of RF was set to 3 , as derived by the number of input predictive variables (in this case 8), while the number of trees (ntree parameter) was set to 100 [58] for each dataset. The accuracy of simulations was assessed against a validation dataset, effectively sub-sampled, through the OOB error calculation. The probability of occurrence for the eight classes (seven pasture macro-types and unclassified pasturelands), as resulting from RF simulations, was converted into presence/absence computing the true skill statistic index (TSS, which avoids an overestimation of those categories that are mostly represented, [59]) maximizing the prediction accuracy of the model. The TSS threshold was then applied to all validation subsets to test the classification error of the proposed threshold. Accordingly, the RF models were applied over the entire dataset to predict site-level probability of occurrence of unclassified pasturelands and pasture macro-types over the entire Italian Alpine chain in the current time period and under RCP 4.5 and 8.5 future climate scenarios in the near (2011-2040) and distant future (2041-2070), as projected by CNRM-ALADIN, ICTP-RGCM4, and CMCC-CCLM4 RCM models.

Tmax_jul, Tmin_jan, Prec_djf, Prec_jja, Prec_mam, and Prec_son of the selected RCMs calculated for both scenarios and time slices were tested for significance with respect to the relevant current data. For this test, a delta change of these variables was calculated with respect to baseline on a pixel basis for each macro type, and the null hypothesis that these samples were different from zero was tested. 
As a result, we obtained a total of 504 test cases corresponding to $3 \mathrm{RCMs} \times 2$ scenarios $\times 2$ time slices $\times 7$ macro-types $\times 6$ variables (Table $\mathrm{S} 1$ ).

The final maps were analyzed as an ensemble of the three RCMs outputs, by ascribing the pasture macro-type resulting more frequent/prevalent (i.e., simulated as present by at least two RCMs within each pixel) among the three climatic models and where at least one RCM simulated the presence of unclassified pasturelands. Results were described for the entire Alpine chain and for two main regions, namely Western and Eastern Alps (as characterized by [31]), when relevant. Tables and Figures related to the Western and Eastern area are reported in the SI.

\section{Results}

\subsection{RF Calibration and Classification Accuracy}

RF classification accuracy was estimated by comparing simulated presence/absence of macro-types against 10,882 grid points of the validation dataset over the climatic baseline period (1970-2000). The cross-calibration (Table 2) between observed and simulated pastures macro-types distribution over the Alpine chain for the present period was shown to be robust, with an overall mean accuracy of 98.7\%. The lowest performance was observed for Festuca gr. rubra (94.2\%), while the highest for Nardus stricta $(99.2 \%)$. The TSS, calculated for each single macro-type, resulted in any case higher than 0.95 (data not shown).

Table 2. Confusion matrix of Random Forest (RF) between observed and simulated pasture macro-types occurrence classification over the Italian Alpine chain for the present period (baseline 1970-2000). $\mathrm{RF}$ accuracy is reported in percentage (\%). SP stands for pastures encroached by shrub species; CC for pastures dominated by Carex curvula; CF for pastures dominated by Carex firma; NS for pastures dominated by Nardus stricta; FR for pastures dominated by Festuca gr. rubra; SV for pastures dominated by Sesleria varia and XS for pastures dominated by xeric species.

\begin{tabular}{|c|c|c|c|c|c|c|c|c|c|c|}
\hline & & \multicolumn{8}{|c|}{ Simulated } & \multirow{2}{*}{ RF Accuracy (\%) } \\
\hline & & SP & $\mathrm{CC}$ & CF & NS & FR & XS & SV & Observed & \\
\hline \multirow{8}{*}{ Observed } & $\mathrm{SP}$ & 1531 & 8 & 1 & 16 & 0 & 4 & 9 & 1569 & 97.6 \\
\hline & $\mathrm{CC}$ & 2 & 1651 & 0 & 6 & 0 & 0 & 5 & 1664 & 99.2 \\
\hline & $\mathrm{CF}$ & 6 & 0 & 508 & 3 & 0 & 1 & 5 & 523 & 97.1 \\
\hline & NS & 3 & 3 & 0 & 3516 & 0 & 5 & 2 & 3529 & 99.6 \\
\hline & FR & 3 & 1 & 0 & 6 & 211 & 0 & 3 & 224 & 94.2 \\
\hline & XS & 0 & 1 & 0 & 19 & 0 & 1070 & 1 & 1091 & 98.1 \\
\hline & SV & 0 & 4 & 6 & 13 & 1 & 5 & 2253 & 2282 & 98.7 \\
\hline & Simulated & 1545 & 1668 & 515 & 3579 & 212 & 1085 & 2278 & & 98.7 \\
\hline
\end{tabular}

The relative importance of every predicting variable in the classification process was determined via the permutation of each variable in the calibration process, and testing the relevant accuracy of the results (mean decrease accuracy, MDA). The more important a variable is in the accuracy of the prediction, the higher is the relevant MDA (Figure 1). The results indicated that the most important variables were maximum air temperature of July (Tmax_jul), followed by soil $\mathrm{pH}$. By contrast, slope and spring precipitation (Prec_mam) yielded the lowest importance as drivers of the presence of a specific macro-type.

The partial dependence plot resolved for Tmax_jul (see Figure S1) indicated that each single macro type has a specific climatic niche, where xeric species (XS) are the most demanding with monthly temperatures exceeding $20^{\circ} \mathrm{C}$, followed by Festuca rubra (FR) with a higher probability of detection for temperatures higher than $15^{\circ} \mathrm{C}$. The presence of shrubs (SP) is centered on temperatures $\sim 12{ }^{\circ} \mathrm{C}$, whereas that of Nardus stricta (NS) has a peak around $10^{\circ} \mathrm{C}$, similar to Sesleria varia (SV). Carex curvula (CC) has a range included between $\sim 5^{\circ}$ and $\sim 12.5^{\circ} \mathrm{C}$ and the same may be applied to Carex firma (CF). 


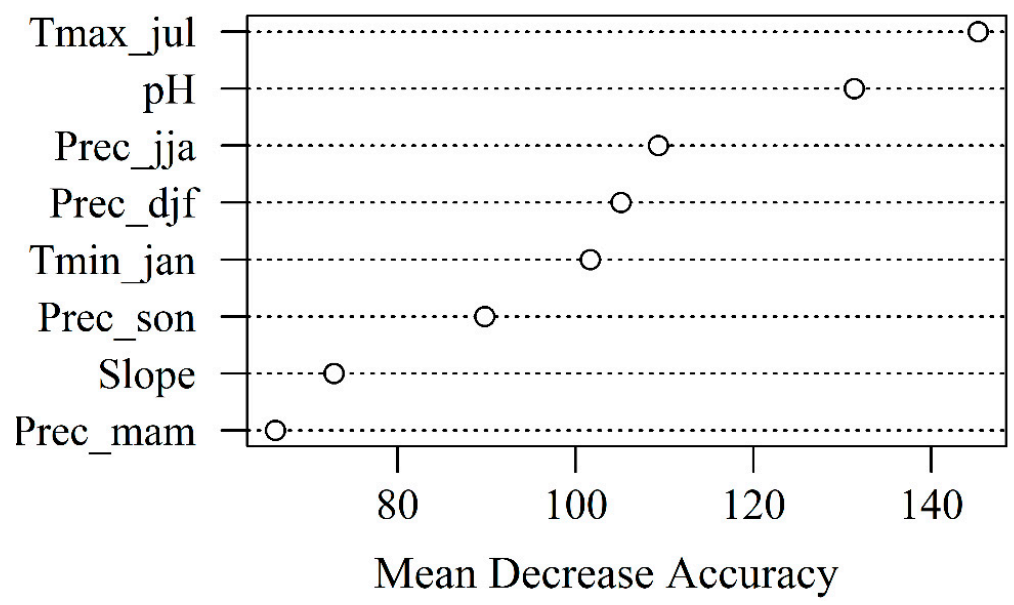

Figure 1. Relative importance of climatic variables, expressed as mean decrease accuracy, in the classification process as derived from random forest calibration. Variables are $\mathrm{pH}$; slope; Tmax_jul: monthly average maximum temperature of July; Tmin_jan: monthly average minimum temperature of January; Prec_djf, Prec_mam, Prec_jja, and Prec_son cumulated precipitation of winter, spring, summer and autumn seasons, respectively.

\subsection{Climate Analysis}

Climate data for the future, as an ensemble, reported a low variability in the simulation of delta change $(\Delta)$ of Tmin_jan compared to the present, with a general trend of the median to increase under future climate conditions (Figure 2) without any relevant difference between the Eastern (Figure S2a) and Western (Figure S3a) areas of the chain, although the Western Alps showed higher increases $\left(+3.6^{\circ} \mathrm{C}\right)$ than the East $\left(+2{ }^{\circ} \mathrm{C}\right)$ with respect to the present. According to the median values, the highest $\Delta$ of Tmin_jan was found for 2041-2070 under RCP4.5 $\left(+2.7^{\circ} \mathrm{C}\right)$ and RCP8.5 $\left(+3.1^{\circ} \mathrm{C}\right)$ (Figure 2a). The pattern was similar for Tmax_jul, where the highest $\Delta$ of the median values were found for 2041-2070 under RCP4.5 $\left(\Delta=+2.1^{\circ} \mathrm{C}\right)$ and RCP8.5 $\left(\Delta=+2.5^{\circ} \mathrm{C}\right)$ (Figure 2b).

Concerning seasonal cumulative precipitation, the modeling ensemble indicated high variability in the simulation of delta change $(\Delta)$ of precipitation compared to the present, showing contrasting patterns of the median among seasons, time-slices, and climate scenarios. The median values of future winter precipitation (Prec_djf) resulted as very close to the median value of the present $(168 \mathrm{~mm})$ under all climate scenarios and time-slices, with the only exception being 2041-2070 under RCP8.5 $(\Delta=+15 \mathrm{~mm}$ ) (Figure 2c). This is mainly due to contrasting patterns between the two areas, namely slight decreases of Prec_djf (up to $\Delta=-50 \mathrm{~mm}$ ) in the Eastern area, whereas relevant increases in the Western Alps (up to $+120 \mathrm{~mm}$ ) (Figures S2c and S3c, respectively). Spring precipitation (Prec_mam) showed a slight increase under all climate scenarios and time-slices compared to the present $(244 \mathrm{~mm})$, with the only exception being 2041-2070 under RCP4.5, where a negligible decrease was observed $(\Delta=-6 \mathrm{~mm}$ ) (Figure 2d). The same pattern was observed for the Western Alps, while the Eastern Alps showed decreases (up to $\Delta=-60 \mathrm{~mm}$ ) with respect to the present in both scenarios and time slices (Figure S2d). According to the median values, summer precipitation (Prec_jja) suggested the highest decrease under all time-slices and scenarios compared to the present $(350 \mathrm{~mm})$, without any particular difference between the two areas of the chain (Figure S2e,f). Specifically, the highest $\Delta$ in precipitation was found for 2041-2070 under RCP4.5 $(\Delta=-130 \mathrm{~mm})$ and RCP8.5 $(\Delta=-137 \mathrm{~mm})$ (Figure 2e). Finally, autumnal precipitation (Prec_son) showed a very slight decrease in the median values for all time-slices and climate scenarios compared to the present $(276 \mathrm{~mm})$. The only exception was for 2011-2040 under RCP8.5, where no change was detected when analyzing the entire chain (Figure 2f). This was determined by a contrasting pattern between the two areas, namely a decrease in the Eastern Alps (up to $\Delta=-90 \mathrm{~mm}$ ) (Figure S2f) and increases (up to $\Delta=+50 \mathrm{~mm}$ ) in the Western areas (Figure S3f). 

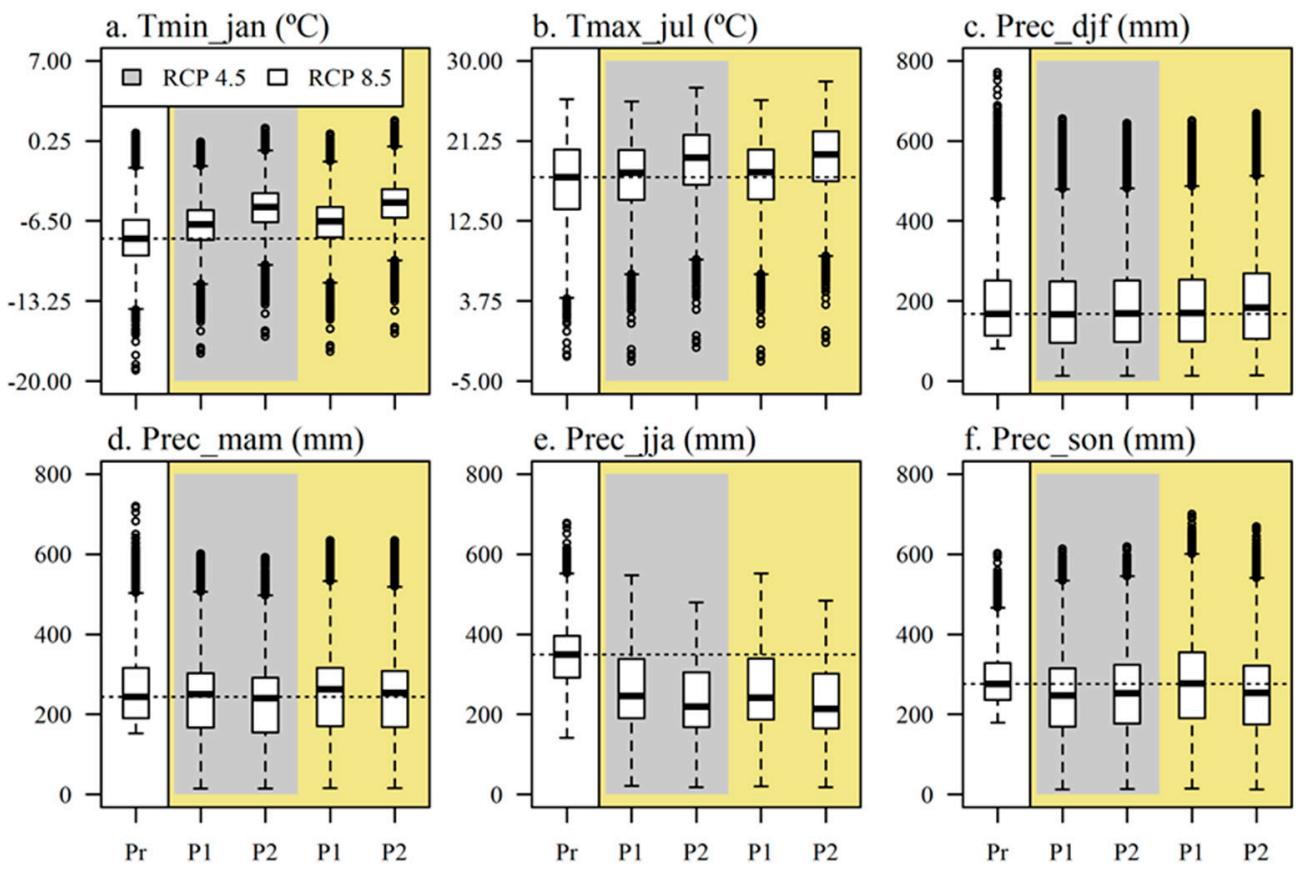

Figure 2. Trends in independent climatic variables (Tmin_jan = Tmin in January (a), Tmax_jul = Tmax in July (b), and the four seasonal cumulated precipitations, namely Prec_djf (c), Prec_mam (d), Prec_jja (e), Prec_son (f)) calculated over multiple years using the modelling ensemble (EN), for two climate scenarios (RCP 4.5 and 8.5) and time-slices (P1 = 2011-2040 and P2 = 2041-2070, respectively) compared to the present ( $P R=1970-2000)$. Black lines show the median while the dotted line represents the median of the present along the scenarios. Boxes delimit the 25 th and 75 th percentiles. Whiskers are 10th and 90th percentiles.

The statistical analysis of the climate across the entire chain evidenced that in more than $90 \%$ of test cases, the deltas between present and future climatic variables were statistically different from zero (data not shown).

\subsection{Altitude Pattern Dynamics of Pasture Macro-Types Suitability}

The seven macro-types showed different ranges of variations in their altitudinal suitability in response to the projected climate change (Figure 3). Pastures dominated by Carex curvula (CC) (Figure 3a), Nardus stricta (NS) (Figure 3d), and Sesleria varia (SV) (Figure 3f) did not show a relevant shift in altitude with respect to the present, considering all time-slices and climate scenarios. The same pattern was observed between the two regions analyzed (Figures S4 and S5) for the three macro-types. In pastures dominated by Carex firma (CF) (Figure 3b), the model median tended to increase under all time-slices and future scenarios, with particular relevance to the period 2041-2070 under RCP8.5, where CF altitude increased by +405 m over the Eastern Alps (Figure S4). On the contrary, the elevation range of pastures dominated by Festuca gr. rubra (FR) (Figure 3c) tended to decrease, as compared to the present period, under all time-slices and future scenarios $(-217 \mathrm{~m}$, on average) over the Western area of the Alps (Figure S5). The same trend was observed for pastures dominated by shrub species (SP) over the entire Alpine chain (Figure 3e), exhibiting a decrease in its elevation range, under all time-slices and future scenarios, with the only exception being 2041-2070 under RCP4.5 $(2200 \mathrm{~m})$, where it was much higher than the present (1832 m). In the distant future (2041-2070), SP showed contrasting trends across the Eastern Alps (Figure S4), namely increases up to $+600 \mathrm{~m}$ under RCP4.5, whereas decreases up to $-200 \mathrm{~m}$ under RCP8.5 with respect to the present. The Western area showed an increasing of altitudes of SP in both time slices and scenarios with respect to the present, more relevant for RCP4.5 in the distant future (Figure S5). Pastures dominated by xeric species (XS, Figure 3g) exhibited a progressive increase of their altitudinal range from 2011-2040 (1619 m, average of both 
scenarios) to 2041-2070 (1845 m), more evident across the Eastern than Western Alps (Figures S4 and S5, respectively). The absence of information for 2041-2070 under RCP4.5 indicated that the model did not simulate any presence of both macro-types for that period.
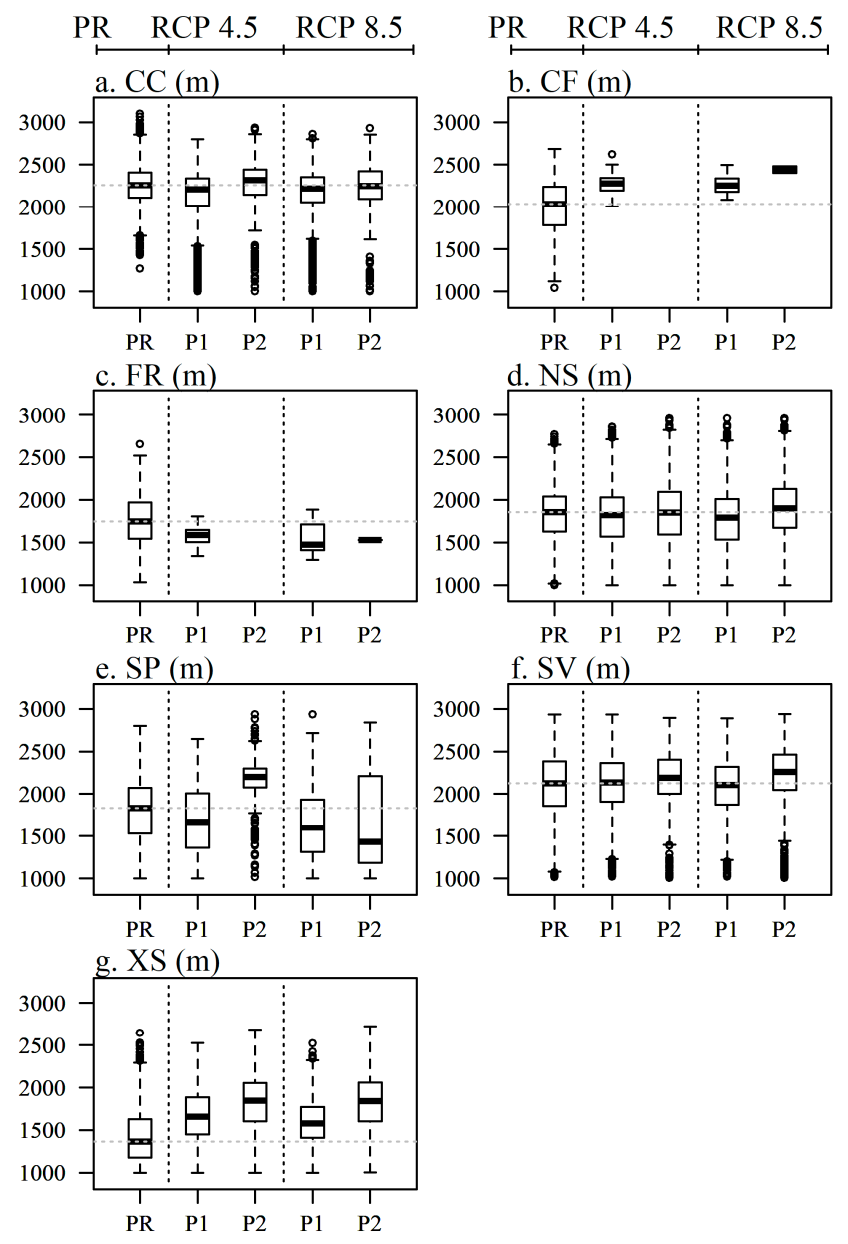

Figure 3. Changes in altitude as reported by the modeling ensemble for each of the seven single macro-types calculated over multiple years for two climate scenarios (RCP 4.5 and RCP 8.5) and time-slices (P1 = 2011-2040 and P2 = 2041-2070, respectively) compared to the present (PR = 1970-2000). Black lines show the median of the altitude calculated by the modeling ensemble, while the dotted line represents the median of the altitude for the present along the scenarios. Boxes delimit the 25th and 75th percentiles. Whiskers are 10th and 90th percentiles.

\subsection{Global Dynamics of Alpine Pasturelands Suitability}

Under future climatic conditions, the Alpine pastures suitability showed an overall decrease with respect to the present (Table 3). The modeling ensemble suggested the highest decrease for 2041-2070, with an estimated reduction of 35\% and $40 \%$ under RCP8.5 and RCP4.5, respectively. In the distant future (2041-2070), this reduction affected more the Eastern area of the chain, losing up to $-45 \%$ and $-40 \%$ of pastures under RCP4.5 and 8.5 scenario, than the Western Alps, depicting a loss up to $-34 \%$ and $-30 \%$ under RCP4.5 and 8.5, respectively, with respect to the present (Tables S2 and S3). However, even in the near future (2011-2040), pasture suitability is found to considerably decrease compared to the present, with an estimated reduction in the range 19-23\% under both RCPs (Table 3). In the near future (2011-2040), the main losses will affect the Western Alps under the RCP8.5 (-25\%) with respect to the Eastern Alps (-16\%), while the trend was opposite under RCP4.5 scenario, where suitability of pastures located across the Western Alps decreased by $-22 \%$ and Eastern Alps by $-24 \%$ with respect to the present (Tables S2 and S3). 
Table 3. Current Alpine occurrence (in terms of number of pixels, i.e., 100 ha wide each) of unclassified pasturelands and expected changes (\%) of suitability under future climate conditions, as reported by the three regional circulation models (RCMs) and their ensemble, time slices (2011-2070 and 2071-2100), and RCP scenarios (4.5 and 8.5).

\begin{tabular}{|c|c|c|c|c|c|c|c|c|c|}
\hline \multirow[b]{2}{*}{$\mathrm{RCM}$} & \multicolumn{5}{|c|}{ Number of Pixels } & \multicolumn{4}{|c|}{$\%$} \\
\hline & Present & $\mathbf{R C P}$ & 4.5 & RCP & 8.5 & RCP & 4.5 & $\mathrm{RCF}$ & 8.5 \\
\hline-- & -- & 2011-2040 & 2041-2070 & 2011-2040 & 2041-2070 & 2011-2040 & 2041-2070 & 2011-2040 & 2041-2070 \\
\hline Aladin & 20,874 & 19,557 & 16,704 & 18,931 & 16,712 & $-6 \%$ & $-20 \%$ & $-9 \%$ & $-20 \%$ \\
\hline CMCC & 20,874 & 13,130 & 11,225 & 15,037 & 11,289 & $-37 \%$ & $-46 \%$ & $-28 \%$ & $-46 \%$ \\
\hline ICTP & 20,874 & 15,507 & 93,92 & 16,497 & 12,548 & $-26 \%$ & $-55 \%$ & $-21 \%$ & $-40 \%$ \\
\hline Ensemble & 20,874 & 16,065 & 12,440 & 16,822 & 13,516 & $-23 \%$ & $-40 \%$ & $-19 \%$ & $-35 \%$ \\
\hline
\end{tabular}

Looking at the single RCM employed, the lowest impacts were reported by Aladin, with a decrease of pasture suitability in a range form $-6 \%$ and $-20 \%$ for all time-slices and climate scenarios. By contrast, the highest impacts were indicated by CMCC for all time-slices and climate scenarios, with the sole exception of the period 2041-2070 under RCP4.5, where the highest pasture decrease $(-55 \%)$ was reported by ICTP.

\subsection{Pasture Macro-Type Analysis under Future Conditions}

\subsubsection{Changes of Pasture Macro-Type Suitability}

The seven macro-types showed different dynamics under future climate conditions, ranging from a large decrease for some, to slight increases for others (Table 4 and Figure 4 when analyzing the entire Alpine chain), depending on the region analyzed (Tables S3 and S4). Specifically, shrub species (SP) strongly decreased for 2041-2070, with the highest reduction under RCP4.5 (-79\%) rather than RCP8.5 $(-66 \%)$ across the entire Alpine chain, where the Western area accounted for the highest decreases $(-94 \%)$ with respect to the Eastern $(-64 \%)$ (Tables S4 and S3, respectively). Pastures dominated by Carex curvula (CC) reported a similar decrease for 2011-2040 and 2041-2070 time slices with losses ranging from $-67 \%$ to $-75 \%$ for RCP 4.5 and $-61 \%$ to $-74 \%$ for RCP 8.5 climate scenarios. The main reductions of CC occurred more in the Eastern Alps in the distant future $(-82 \%)$ compared to the Western $(-69 \%)$, while in the near future an opposite trend was projected between the two regions $(-54 \%$ and $-73 \%$ for the Eastern and Western Alps, respectively). Pastures dominated by Carex firma (CF) indicated very high decreases for 2011-2040 under RCP4.5 (-81\%) and RCP8.5 $(-76 \%)$, with a complete loss of suitable areas for 2041-2070 under both RCP climate scenarios ( $-99 \%$ and $-100 \%$, for 4.5 and 8.5 , respectively). The main losses of CF resulted in the Eastern Alps (-79\% and $-100 \%)$ with respect to the Western area $(-34 \%$ and $-84 \%)$. Areas suited to pastures dominated by Nardus stricta (NS) slightly decreased in 2041-2070 under RCP4.5 (-21\%) and RCP8.5 (-16\%), while for 2011-2040 they showed almost no change $(-1 \%)$ under RCP4.5 and a slight increase $(+8 \%)$ under RCP8.5. These NS increases were in the Eastern Alps only ( $+14 \%$ in the near future). Pastures dominated by Festuca gr. rubra (FR) showed relevant decreases in the near future (2011-2040) in both RCP scenarios $(-59 \%$ and $-86 \%$ for RCP4.5 and 8.5, respectively), while a complete loss is projected in the distant future (2041-2070) for both RCP scenarios (-98\% and $-93 \%$ for RCP4.5 and RCP8.5, respectively). The lowest losses of FR in the near future (2011-2040) resulted across the Western Alps (-59\%), while in the 2041-2070 time-slice both Eastern and Western Alpine regions had a complete loss of FR macro-type. Considering the entire Alpine chain, xeric species (XS) in 2011-2040 showd no change or a slight decrease $(-4 \%)$ under RCP4.5 and RCP8.5, respectively. Conversely, in the distant future (2041-2070) areas suited to XS increased under both RCP4.5 (+13\%, ) and RCP8.5 (+7\%). These contrasting results were derived from an opposite trend between the two Alpine regions. Specifically, the Western Alps had expansions of areas suited to XS in both the time slices considered $(+78 \%$ and $+85 \%$ in the near and distant future, respectively), whilst the Eastern area showed decreases ranging from $-58 \%$ to $-43 \%$ in $2011-2040$ 
and 2041-2070, respectively. Finally, pastures dominated by Sesleria varia (SV) showed the lowest $(-27 \%)$ and the highest (-57\%) reductions under RCP4.5 for 2011-2040 and 2041-2070, respectively, while a reduction of around $-44 \%$ was found for both time-slices under RCP8.5. In the distant future (2041-2070), the main reductions of SV suitability resulted across the Eastern Alps (-64\%), while, in the near future (2011-2040), the two areas showed a similar pattern.

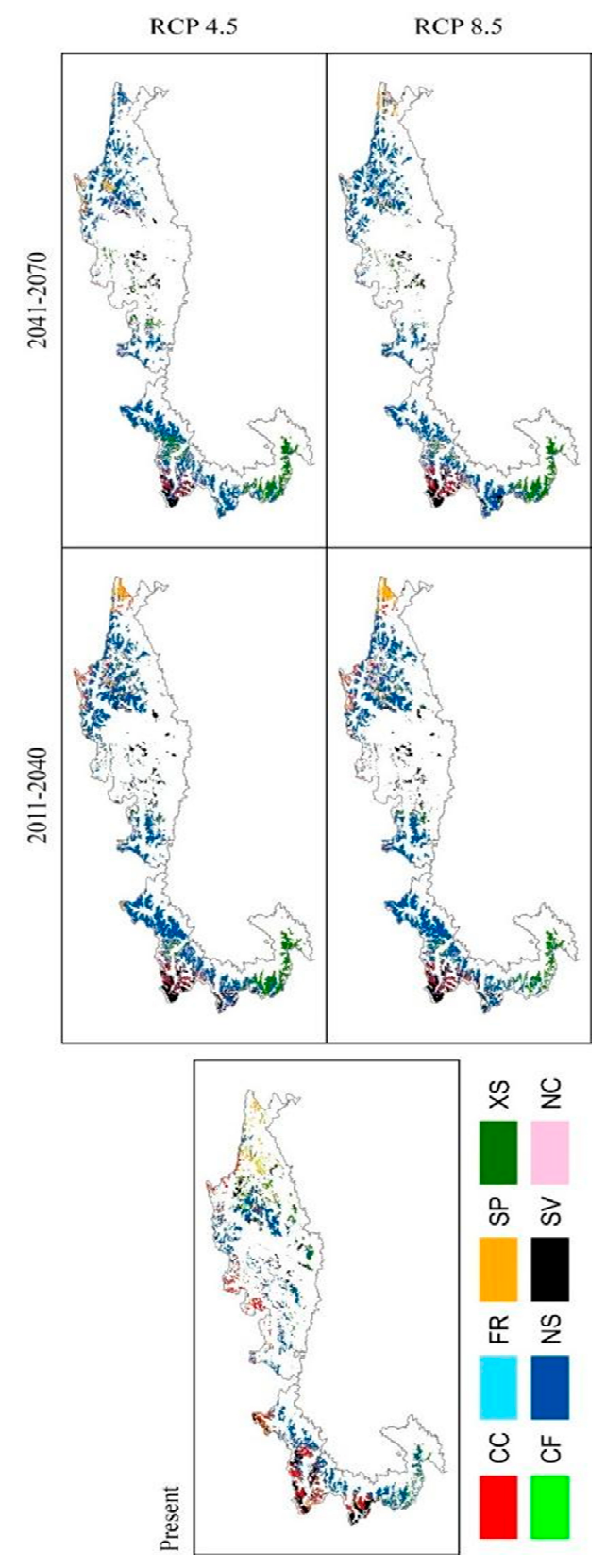

Figure 4. Grid cell map representing the distribution of the identified seven pasture macro-types across the Italian Alps in the present (left hand of the figure) and ensembled future time slices and RCP scenarios (right side of the figure). In red, pastures dominated by Carex curvula (CC); in light green, pastures dominated by Carex firma (CF); in light blue, pastures dominated by Festuca rubra (FR); in dark blue, pastures dominated by Nardus stricta (NS); in orange, pastures dominated by shrubs (SP); in black, pastures dominated by Sesleria varia (SV); in dark green, pastures dominated by xeric species (XS); in pink, unclassified (NC) pasturelands, located above $1000 \mathrm{~m}$. For tabular data across the two main regions (Eastern and Western), see Tables S4 and S5. 
Table 4. Changes of pasture macro-type suitability under future climate scenarios (RC 4.5 and 8.5) and time slices (2011-2040, 2041-2070) with respect to current climate conditions, as reported by the table, 100 ha wide each on the left side of the table; percentage of variation with respect to the present on the center of the table (light grey background), averages of percentage of variation for both RCP 4.5 and 8.5 scenarios (dark grey) on the right side of the table (RCP ensemble).

\begin{tabular}{|c|c|c|c|c|c|c|c|c|c|c|c|c|}
\hline & \multicolumn{2}{|r|}{$\begin{array}{l}\text { Scenario } \\
\text { Present }\end{array}$} & \multicolumn{2}{|c|}{ RCP 4.5} & \multicolumn{2}{|c|}{ RCP 8.5} & \multicolumn{2}{|c|}{ RCP 4.5} & \multicolumn{2}{|c|}{ RCP 8.5} & \multicolumn{2}{|c|}{ RCP Ensemble } \\
\hline & RCM & Present & 2011-2040 & 2041-2070 & 2011-2040 & 2041-2070 & 2011-2040 & 2041-2070 & 2011-2040 & $2041-2070$ & 2011-2040 & 2041-2070 \\
\hline & $-\cdots$ & $\cdots$ & \multicolumn{4}{|c|}{$\mathrm{N}^{\circ}$ of Pixels } & \multicolumn{4}{|c|}{$\%$} & \multicolumn{2}{|c|}{$\%$} \\
\hline Shrub species (SP) & & 2332 & 1168 & 498 & 1490 & 789 & -50 & -79 & -36 & -66 & -43 & -72.5 \\
\hline Carex curvula (CC) & & 3026 & 988 & 748 & 1188 & 790 & -67 & -75 & -61 & -74 & -64 & -74.5 \\
\hline Carex firma (CF) & & 617 & 120 & 7 & 150 & 2 & -81 & -99 & -76 & -100 & -78.5 & -99.5 \\
\hline Nardus stricta (NS) & Ensemble & 9303 & 9183 & 7355 & 10058 & 7842 & -1 & -21 & 8 & -16 & 3.5 & -18.5 \\
\hline Festuca rubra (FR) & & 256 & 104 & 5 & 36 & 18 & -59 & -98 & -86 & -93 & -72.5 & -95.5 \\
\hline Xeric species (XS) & & 2219 & 2217 & 2499 & 2123 & 2367 & 0 & 13 & -4 & 7 & -2 & 10 \\
\hline Sesleria varia (SV) & & 3121 & 2284 & 1329 & 1777 & 1708 & -27 & -57 & -43 & -45 & -35 & -51 \\
\hline
\end{tabular}




\subsubsection{Changes in Pasture Macro-Types Composition}

The expected future pasture composition for 2011-2040 and 2041-2070 under RCP4.5 and RCP8.5 indicated a general reduction in pasture biodiversity in the next decades, with the highest decreases expected in the distant future (2041-2070) (Table 5). Variations in pasture composition were mainly driven by time-slices rather than the climate scenarios, and while most of pasture macro-types showed a general decrease in their suitability, the most hardy and less palatable species, such as Nardus stricta (NS) and xeric species (XS), showed increases in their occurrence over areas currently suitable for other macro-types (Table 6).

Table 5. Current and expected Alpine pasture composition (\%) for 2011-2040 and 2041-2070 under RCP4.5 and RCP8.5 as resulting from the modeling ensemble. In brackets, changes for each macro-type compared to the present.

\begin{tabular}{|c|c|c|c|c|c|c|}
\hline \multirow{2}{*}{ Macro-Types } & \multicolumn{2}{|l|}{$\mathrm{RCM}$} & \multicolumn{2}{|c|}{$\mathrm{RCP45}$} & \multicolumn{2}{|c|}{ RCP85 } \\
\hline & $\ldots$ & Present & 2011-2040 & 2041-2070 & 2011-2040 & 2041-2070 \\
\hline Shrub species (SP) & \multirow{8}{*}{ Ensemble } & $11 \%$ & $7 \%(-4 \%)$ & $4 \%(-7 \%)$ & $9 \%(-2 \%)$ & $6 \%(-5 \%)$ \\
\hline Carex curvula (CC) & & $14 \%$ & $6 \%(-8 \%)$ & $6 \%(-8 \%)$ & $7 \%(-7 \%)$ & $6 \%(-8 \%)$ \\
\hline Carex firma (CF) & & $3 \%$ & $1 \%(-2 \%)$ & $0 \%(-3 \%)$ & $1 \%(-2 \%)$ & $0 \%(-3 \%)$ \\
\hline Nardus stricta (NS) & & $45 \%$ & $57 \%(+12 \%)$ & $59 \%(+14 \%)$ & $60 \%(+15 \%)$ & $58 \%(+13 \%)$ \\
\hline Festuca rubra (FR) & & $1 \%$ & $1 \%(0 \%)$ & $0 \%(-1 \%)$ & $0 \%(-1 \%)$ & $0 \%(-1 \%)$ \\
\hline Xeric species (XS) & & $11 \%$ & $14 \%(+3 \%)$ & $20 \%(+9 \%)$ & $13 \%(+2 \%)$ & $18 \%(+7 \%)$ \\
\hline Sesleria varia (SV) & & $15 \%$ & $14 \%(-1 \%)$ & $11 \%(-4 \%)$ & $11 \%(-4 \%)$ & $13 \%(-2 \%)$ \\
\hline Total & & $100 \%$ & $100 \%$ & $100 \%$ & $100 \%$ & $100 \%$ \\
\hline
\end{tabular}

Table 6. Expected suitability change (in percentage) within each macro-type as reported by modeling ensemble for 2011-2040 and 2041-2070 averaged for both climate scenarios. The percentages correspond to the new suitable area for each macro-type within the total future extent of pastureland suitability.

\begin{tabular}{|c|c|c|c|c|c|c|c|c|c|}
\hline & \multirow{2}{*}{ Time-Slice } & \multirow{2}{*}{ SP } & \multirow{2}{*}{$\mathrm{CC}$} & \multirow{2}{*}{ CF } & \multirow{2}{*}{ NS } & \multirow{2}{*}{ FR } & \multirow{2}{*}{ XS } & \multirow{2}{*}{ SV } & \multirow{2}{*}{$\begin{array}{c}\text { Total } \\
\text { Occurrence }\end{array}$} \\
\hline & & & & & & & & & \\
\hline Shrub species (SP) & \multirow{7}{*}{ 2011-2040 } & $31.7 \%$ & $9.0 \%$ & $9.5 \%$ & $29.2 \%$ & $1.6 \%$ & $1.3 \%$ & $17.9 \%$ & $100 \%$ \\
\hline Carex curvula (CC) & & $19.1 \%$ & $42.6 \%$ & $10.0 \%$ & $13.1 \%$ & $0.5 \%$ & $0.4 \%$ & $14.5 \%$ & $100 \%$ \\
\hline Carex firma $(\mathrm{CF})$ & & $2.8 \%$ & $6.2 \%$ & $39.1 \%$ & $12.1 \%$ & $3.5 \%$ & $0.0 \%$ & $36.5 \%$ & $100 \%$ \\
\hline Nardus stricta (NS) & & $14.3 \%$ & $12.4 \%$ & $3.5 \%$ & $56.8 \%$ & $1.5 \%$ & $2.1 \%$ & $9.6 \%$ & $100 \%$ \\
\hline Festuca rubra (FR) & & $2.3 \%$ & $7.5 \%$ & $0.0 \%$ & $50.9 \%$ & $13.0 \%$ & $21.8 \%$ & $4.6 \%$ & $100 \%$ \\
\hline Xeric species (XS) & & $4.0 \%$ & $5.1 \%$ & $0.2 \%$ & $59.1 \%$ & $1.1 \%$ & $27.5 \%$ & $3.0 \%$ & $100 \%$ \\
\hline Sesleria varia (SV) & & $10.1 \%$ & $19.9 \%$ & $5.1 \%$ & $21.7 \%$ & $1.8 \%$ & $1.5 \%$ & $40.2 \%$ & $100 \%$ \\
\hline Shrub species (SP) & \multirow{7}{*}{ 2041-2070 } & $17.1 \%$ & $18.1 \%$ & $17.2 \%$ & $18.7 \%$ & $1.7 \%$ & $0.8 \%$ & $26.6 \%$ & $100 \%$ \\
\hline Carex curvula (CC) & & $20.2 \%$ & $44.5 \%$ & $6.0 \%$ & $12.6 \%$ & $0.7 \%$ & $0.2 \%$ & $16.1 \%$ & $100 \%$ \\
\hline Carex firma $(\mathrm{CF})$ & & $3.2 \%$ & $3.2 \%$ & $78.2 \%$ & $0.0 \%$ & $0.0 \%$ & $0.0 \%$ & $15.7 \%$ & $100 \%$ \\
\hline Nardus stricta (NS) & & $15.9 \%$ & $16.5 \%$ & $6.6 \%$ & $42.3 \%$ & $1.8 \%$ & $1.8 \%$ & $15.3 \%$ & $100 \%$ \\
\hline Festuca rubra (FR) & & $6.0 \%$ & $7.2 \%$ & $0.0 \%$ & $57.0 \%$ & $2.4 \%$ & $16.1 \%$ & $11.5 \%$ & $100 \%$ \\
\hline Xeric species (XS) & & $6.7 \%$ & $11.9 \%$ & $0.6 \%$ & $58.4 \%$ & $1.0 \%$ & $14.9 \%$ & $6.6 \%$ & $100 \%$ \\
\hline Sesleria varia (SV) & & $11.0 \%$ & $25.2 \%$ & $2.3 \%$ & $18.5 \%$ & $0.8 \%$ & $1.3 \%$ & $41.2 \%$ & $100 \%$ \\
\hline
\end{tabular}

Pastures dominated by shrub species (SP) and Carex Curvula (CC) considerably decreased under all time-slices and scenarios compared to the present, particularly for $2041-2070$ ( $-74 \%$ and $-74.5 \%$, respectively; Table 4), each contributing $6 \%$, on average, to the future Alpine pastureland composition (Table 5).

In this dynamic, most of the areas formerly suited to shrub species (SP, $72.5 \%$ ) became suitable for Nardus stricta (NS, 18.7\%), Carex curvula (CC, 18.1\%), Carex firma (CF) (17.2\%), and Sesleria varia (SV, 26.6\%) in the distant future (2041-2070), while areas currently suited to CC are projected to be replaced by SP (20.2\%), NS (12.6\%), and SV (16.1\%) (Table 6). Areas suitable in the present for pastures dominated by Carex firma (CF) and Festuca gr. rubra (FR) are projected to almost disappear (-99.5\% and $-95.5 \%$, Table 4) in the distant future (2041-2070). However, while for Carex firma (CF) the major part of the few areas still present remained suitable for this macro-type (CF, 78.2\%) and $15.7 \%$ became 
more suitable for Sesleria varia (SV), that lost by Festuca gr. rubra became suitable mainly for Nardus stricta $(57 \%)$ and xeric species (16.1\%) (Table 6). Pastures dominated by Sesleria varia (SV), despite decreasing under all time-slices and scenarios and particularly for 2041-2070 (-51\%, Table 4), showed a similar extent $(12 \%$, on average) compared to the present pasture composition (15\%, Table 5). In these dynamics, areas suited to Sesleria varia (SV) maintained on average their extent $(41.2 \%)$ within the current suitable pasturelands; about $42 \%$ of their suitable areas were replaced by Carex curvula (CC, $25.2 \%$ ) and Nardus stricta (NS, 18.5\%), but they increased over pastures currently dominated by shrub species and Carex curvula (Table 6). Pastures dominated by Nardus stricta (NS) slightly decreased for 2041-2070 (-18.5\%), however they showed an increased presence in future pasture composition $(+13.5 \%)$ compared to the present (Table 5). The areas lost by Nardus stricta (NS) were projected to become suitable mainly for shrub species (SP, 15.9\%) and Carex curvula (CC, 16.5\%) and Sesleria varia (SV, 15.3\%), though its general suitability remained high (42.3\%) (Table 6). The NS (Nardus stricta) resulted to be the main competitor in capturing the reduced suitable areas for most macro-types across all time-slices and scenarios, over the whole Italian Alpine chain (Figure 4). Finally, pastures dominated by xeric species (XS) increased in 2041-2070 $(+10 \%$, Table 4$)$, resulting also in an increased presence in the future pasture composition ( $+8 \%$, Table 5$)$ compared to the present $(11 \%)$, in particular in the Western area of the chain. Most losses of pasture macro-types became areas suited to Nardus stricta (NS, 58\%) and Carex curvula (CC, 12\%) (Figure 4).

\section{Discussion}

Alpine pastures are key ecosystems for people living in both mountain and urban areas, as they provide socio-economic and ecosystem services such as tourism, food products, biodiversity, and greenhouse gas mitigation etc. Given the current impacts of climate change on this ecosystem, this study aimed at evaluating the robustness of RF as a tool for estimating the spatial distribution and expected change of the main representative pasture macro-types in terms of their extent, ecological and pastoral importance across the Alps under future climate. In this context, the use of pre-existent spatial datasets coupled with the RF model proved to be robust at predicting potentially suitable macro-type areas of Alpine pastures under current climate conditions. The analysis has primarily taken into account the impact of climate change projections based on two time-slices (2011-2040 and 2041-2070) and most recent climate scenarios (RCP4.5 and RCP8.5) considering the long-lasting influence of species competition, through fitting pasture response to the environmental predictors without covering land abandonment and land-use policies, which strongly affect pastures [36]. Despite the proposed method proving to be robust, some issues should be reported. The delta change approach used for predicting the future climate in this study does not explicitly consider extreme climate events (likely causing negative impacts on pastoral resources, $[60,61])$ and we considered data of the warmest and coldest months of the year as a proxy for climatic extreme (i.e., frost events and heat waves) during the year. However, frequency and intensity of these events is expected to increase in the near future [19].

Moreover, even though it is unquestionable that the living conditions of herbaceous species are dependent on soil temperature rather than air temperature [62], the latter may be used as a proxy of for the former. As an example, Choler [63] demonstrated that soil and air temperatures are closely related and this relationship may be used to rescale daily mean air temperature. Indeed, in a previous work [31], we observed that actually air temperature is actually able to discriminate different kinds of macro-types across the Alps and this is likely related to the fact that air and soil temperatures are closely related.

Modeling ensemble indicated a global reduction of pastures suitability for all time-slices and scenarios, particularly for 2041-2070 where pasture lands decreased within a range of $-35 \%$ to $-40 \%$ with respect to the present period (Table 3), mostly affecting the Eastern Alps (ranges between $-40 \%$ and $-45 \%$ ) than the Western (ranges between $-30 \%$ and $-34 \%$; Tables S2 and S3). The magnitude of this decrease was likely due to the expected changes in climate conditions determining the suitability of each specific macro-type (i.e., optimal conditions for development) in conjunction with 
the available altitudinal space for a shift of the vegetation. The results indicated that projected increase of temperatures raised the optimal climate range of each macro-type to a higher altitude, resulting at the same time in a general spatial reduction of suitable areas. This was also suggested by analyzing the simulated range in which the seven macro-types are currently found (1051-2797; 1746 on average), which in the future is found to be reduced by $-356 \mathrm{~m}$ on average, thus resulting at altitudes ranging from 1225 to 2635 (1411 on average). This warming effect on pasture has been observed by several studies (e.g., [64,65]). The shift of macro-types to a higher altitude clearly resulted in a generalized decrease of the seven macro-types suitability areas across the whole Alpine chain compared to the present. The reduction of this altitudinal range was mainly driven by less space (number of pixels) for expansion of the macro-types typical of the high altitudes (i.e., Carex curvula, Carex firma and Sesleria varia). The altitudinal range reduction found in this study also reflects the observed dynamics in which this shift upwards of pastures is also boosted by the forest line rise [66], lowered by human activities over the centuries [67]. Since the model does not consider pasture management, RF may have simulated the increase of other land-uses (such as forests), which is consistent with studies reporting that with unmanaged pastures the forests tend to move upwards [68]. According to our predictions, the areas currently occupied by pastures will be likely be replaced by forests, because of the coupled effect of treeline upward movement and expected impossibility of greening process at higher elevation [69].

The analysis of change of macro-type occurrence compared to the present also allowed to indicate the expected changes to the entire Alpine pasture composition, distinctly between two main regions (Eastern and Western Alps), and the suitability change within each macro-type along the chain. Considering the entire Alpine chain, results suggested an expected reduction of pastures diversity driven by a slight decrease or, in some circumstances an increase, of the low-quality macro-types suitability (e.g., mainly those characterized by Nardus stricta and by xeric species), the complete loss of pastures dominated by Festuca gr. rubra and Carex firma, and a decrease in the suitability for all the remaining macro-types (Figure 4 and Tables 5 and 6). While changes in pastoral suitability between the two Alpine regions showed similar patterns for most of the macro types, the projected climatic conditions in the Eastern area determined higher losses of areas suited to Carex firma and Festuca gr. rubra with respect to the Western (Tables S4 and S5). Conversely, the expansion of low-quality pasture macro types (i.e., dominated by Nardus stricta and xeric species) affecting the Western Alps only, was mainly determined by the drier and warmer conditions projected in this area in the future (Tables S4 and S5 and Figures S2 and S3). These results suggested not only that the expected climate change may favor the most hardy and low quality species, but also how the change in future climate conditions, which varies along the chain, over unmanaged pastures may affect the interaction between the current communities. For instance, pastures dominated by Carex firma and Carex curvula showed a considerable reduction compared to the present (Table 5), also resulting as missing or very small communities within the future pasture composition (Table 6). These macro-types, generally found at the highest altitude and over calcareous (Carex firma) or acid (Carex curvula) soils, require a microthermal regime and high summer precipitation [45]. Moreover, predicted temperature increase will anticipate snowmelt date and shift precipitation from snow to rain [70]. This will produce an earlier snow disappearance, less water storage in the soil, and an increasing water demand. As a result of these coupled effects, a higher water stress for vegetation is predicted for the growing season and pastoral macro-types more sensitive to this will probably be those growing at higher altitude [71]. The expected temperature increase in conjunction with spring precipitation decreases would suggest shifts upwards for these macro-types. However, the reduced space availability in conjunction with the difficulty of moving into rocky soils may have strongly reduce their future suitability. By contrast, although pastures dominated by Sesleria varia show similar climatic and ecological requirements as those dominated by Carex firma and Carex curvula, they showed lower decreases (Table 5). This was likely due to the fact that pastures dominated by Sesleria varia cover a wider ecological spectrum and higher altitudinal range than Carex firma and Carex curvula [72], determining reductions in space and soil competition 
with the other macro-types, thus resulting in more adaptability under the expected future conditions. Concerning the most xeric and low-medium altitude macro-types, areas suited to pastures dominated by Festuca gr. rubra are expected to disappear, while those dominated by Nardus stricta and xeric species showed contrasting results when comparing the two regions. More specifically, while pastures dominated by Nardus stricta showed increases in the Eastern Alps, xeric species are projected to find their optimal conditions in the Western area under future climatic conditions, with relevant expansions in the distant future. The dynamics of the expected suitability change of this macro-type, characterized by general contrasting climatic and ecological requirements with respect to the median values of Carex firma, Carex curvula, and Sesleria varia [31], were clearly driven by intrinsic ecological characteristics of each macro-type as well as by the fact that RF simulations did not consider the management effect on pastures and on the single pastures macro-type. For instance, the simulated increase of Nardus stricta across the Alpine chain in the future, suggested the ability of this community to spread even under changed climatic conditions. This agrees with the ability of this macro-type to develop over poor N-content soils and its hardiness in adapting to a wider spectrum of climatic conditions [10]. This increase might be also favored by the lack of management, since several studies confirmed that Nardus stricta can find the best development conditions under unmanaged or low grazing intensity areas because of its oligotrophic behavior that can favor the spread of this species in areas with reduced return of animal fertility to soil $[10,73]$. As expected, the simulated increase of xeric species reflected the warmer and drier conditions projected by RCMs for the next decades particularly across the Western Alps, which can widen their ecological spectrum and make them more adaptable and competitive against the other macro-types [74]. By contrast, the losses of pastures suitability dominated by Festuca g. rubra likely involved several factors. First, the expected shift upwards due to the changed climatic conditions may have further decreased the presence of this macro-type already geographically limited on the Alpine chain according to our assessment (Table 1). Second, this macro-type may have strongly suffered the competition with less palatable and hardy species, such as Nardus stricta and xeric species, which may have inhibited the development of pastures dominated by Festuca g. rubra in the Alpine chain. These dynamics can be suggested also by Table 6, where the suitability change of Festuca gr. rubra tends to turn mainly to herbaceous communities dominated by Nardus stricta and xeric species. This agrees with Targetti et al. [44], confirming that pastures dominated by Festuca rubra are inclined to reduce their extents or turn into Nardus stricta macro-types under unmanaged conditions.

\section{Concluding Remarks}

The results of this study demonstrated how the projected climatic conditions will determine an overall reduction of the areas currently suited to natural pasturelands of the Italian Alps and variations in the composition of these ecosystems. The main reductions will likely affect high altitude macro types (i.e., pastures dominated by Carex firma, Carex curvula, and Festuca gr. Rubra) over the entire chain, threatening the unique and rare herbaceous biodiversity characterizing the Alps. Contrasting impacts were evidenced between the Eastern and Western Alps on the future distribution of the more hardy and low quality macro types (i.e., pastures dominated by Nardus stricta and xeric species), projecting relevant expansions of areas suited to Nardus stricta and xeric species across the Eastern and Western Alps, respectively, which should be investigated in more detail. All these impacts pose several challenges concerning the related effects on future pasture characteristics and management. First of all, changed climatic conditions may likely lead to variation in biomass peaks and productivity compared to the present, because of advancing of the spring phenology, delay in autumn phenology, and an earlier timing of maximum photosynthesis [75-79]. Furthermore, losses or decreases of suitability of high-quality macro-types, besides leading to a general decrease in pasture diversification and a general homogenization of the landscape, will likely strongly alter the nutritional value of the mountain grazing areas. Moreover, the expected decrease of high-forage quality macro-types such as Festuca. gr. rubra in favor of Nardus stricta, a non-palatable grass, may result in an overall decrease in pasture quality that could be tackled by more appropriate stocking rates or management techniques [80] or 
by diversifying or mixing livestock species (characterized by different grazing behavior) in order to maximize animal performances and, at the same time, to improve the utilization of these marginal areas [81]. Finally, in the new projected pasture conditions farmers will be forced to provide additional nutrients for livestock feeding in order to guarantee or maintain an adequate production level, though resulting in increase of management costs.

Supplementary Materials: The following are available online at http://www.mdpi.com/2073-4395/10/7/926/s1. Figure S1: Partial dependence plot of the probability of presence of different macro types versus increasing values of Tmax in July. The original data were interpolated using a polynomial function. Figure S2: Eastern Alps, trends in independent climatic variables (Tmin_jan = Tmin in January (a), Tmax_jul = Tmax in July (b), and the four seasonal cumulated precipitations, namely Prec_djf (c), Prec_mam (d), Prec_jja (e), Prec_son (f)) calculated over multiple years using the modeling ensemble (EN), for two climate scenarios (RCP 4.5 and 8.5) and time-slices $(P 1=2011-2040$ and $P 2=2041-2070)$ compared to the present $(P R=1970-2000)$. Black lines show the median while the dotted line represents the median of the present along the scenarios. Boxes delimit the 25 th and 75th percentiles. Whiskers are 10th and 90th percentiles. Figure S3: Western Alps, trends in independent climatic variables (Tmin_jan = Tmin of January (a), Tmax_jul = Tmax of July (b), and the four seasonal cumulated precipitation, namely Prec_djf (c), Prec_mam (d), Prec_jja (e), Prec_son (f)) calculated over multiple years using the modelling ensemble (EN), for two climate scenarios (RCP 4.5 and 8.5) and time-slices (P1 = 2011-2040 and $\mathrm{P} 2=2041-2070$, respectively) compared to the present $(\mathrm{PR}=1970-2000)$. Black lines show the median while the dotted line represents the median of the present along the scenarios. Boxes delimit the 25th and 75th percentiles. Whiskers are 10th and 90th percentiles. Figure S4: Changes in altitude in the Eastern Alps as reported by modelling ensemble for each of the seven single macro-types calculated over multiple years for two climate scenarios (RCP 4.5 and RCP 8.5) and time-slices $(\mathrm{P} 1=2011-2040$ and $\mathrm{P} 2=2041-2070$, respectively) compared to the present $(P R=1970-2000)$. Black lines show the median of the altitude calculated by the modelling ensemble, while the dotted line represents the median of the altitude for the present along the scenarios. Boxes delimit the 25th and 75th percentiles. Whiskers are 10th and 90th percentiles. Figure S5: Changes in altitude in the Western Alps as reported by modelling ensemble for each of the seven single macro-types calculated over multiple years for two climate scenarios (RCP 4.5 and RCP 8.5) and time-slices (P1 = 2011-2040 and P2 = 2041-2070, respectively) compared to the present $(P R=1970-2000)$. Black lines show the median of the altitude calculated by the modelling ensemble, while the dotted line represents the median of the altitude for the present along the scenarios. Boxes delimit the 25th and 75th percentiles. Whiskers are 10th and 90th percentiles. Table S1: Test for delta change significantly different from 0 . The test was performed considering the delta changes samples for each RCMs, variable, and time slice extracted from each macro-type area as delimited in the present period. For each sample, the null hypothesis that these samples were different from zero was tested $\left({ }^{*}\right.$ significant for $p<0.05,{ }^{* *}$ significant for $p<0.01,{ }^{* * *}$ significant for $p<0.001$ ). Table S2: Current Eastern alpine occurrence (in terms of number of pixels, i.e., 100 ha wide each) of unclassified pasturelands and expected changes (\%) of suitability under future climate conditions, as reported by the three regional circulation models (RCMs) and their ensemble, time slices (2011-2040 and 2041-2070) and RCP scenarios (4.5 and 8.5). Table S3: Current Western alpine occurrence (in terms of number of pixels, i.e., 100 ha wide each) of unclassified pasturelands and expected changes (\%) of suitability under future climate conditions, as reported by the three regional circulation models (RCMs) and their ensemble, time slices (2011-2070 and 2071-2100) and RCP scenarios (4.5 and 8.5). Table S4: Changes of pasture macro-type suitability of the Eastern Alps under future climate scenarios (RC 4.5 and 8.5) and time slices (2011-2040, 2041-2070) with respect to current climate conditions, as reported by the RCMs modelling ensemble. RCP ensemble reports averages of percentage of both RCP 4.5 and 8.5 scenarios. Absolute values (number of pixels, i.e., 100 ha wide each) on the left hand of the table; percentage of variation with respect to the present on the center right hand of the table (light grey background), averages of percentage of variation for both RCP 4.5 and 8.5 scenarios (dark grey) on the right hand of the table (RCP ensemble). Table S5: Changes of pasture macro-type suitability of the Western Alps under future climate scenarios (RC 4.5 and 8.5) and time slices (2011-2040, 2041-2070) with respect to current climate conditions, as reported by the RCMs modelling ensemble. RCP ensemble reports averages of percentage of both RCP 4.5 and 8.5 scenarios. Absolute values (number of pixels, i.e., 100 ha wide each) on the left hand of the table; percentage of variation with respect to the present on the center right hand of the table (light grey background), averages of percentage of variation for both RCP 4.5 and 8.5 scenarios (dark grey) on the right hand of the table (RCP ensemble).

Author Contributions: Conceptualization, L.B. and C.D.; methodology, M.M. and C.D.; software, S.C.-A., M.M., and C.D.; validation, S.C.-A. and C.D.; formal analysis, S.C.-A., M.M., and C.D.; investigation, S.C.-A., M.M., G.A., and C.D.; resources, C.D. and M.B.; data curation, S.C.-A., M.M., and L.B.; writing-original draft preparation, L.B., C.D., G.A., and M.M.; writing-review and editing, A.P., F.C., C.V., N.S., and G.P.; visualization, L.B., C.D., and G.A.; supervision, M.M., C.D., and L.B.; project administration, C.D., G.A., and M.B.; funding acquisition, C.D., G.A., and M.B. All authors have read and agreed to the published version of the manuscript.

Funding: The research leading to these results was supported by the LIFE PASTORALP project (LIFE16 CCA/IT/000060), co-funded by the European Union's LIFE Programme, Climate change adaptation action sub-programme.

Conflicts of Interest: The authors declare no conflict of interest. 


\section{References}

1. Organisation for Economic Co-Operation and Development. Climate Change in the European Alps; OECD Publishing: Paris, France, 2007; ISBN 9789264031685.

2. Sundseth, K. Natura 2000 in the Alpine Region; European Communities: Luxembourg, 2009; p. 15.

3. Bengtsson, J.; Bullock, J.M.; Egoh, B.; Everson, C.; Everson, T.; O'Connor, T.; O'Farrell, P.J.; Smith, H.G.; Lindborg, R. Grasslands-More important for ecosystem services than you might think. Ecosphere 2019, 10, e02582. [CrossRef]

4. The Economics of Ecosystems and Biodiversity. The Economics of Ecosystems and Biodiversity: Mainstreanubg the Economics of Nature: A Synthesis of the Approach, Conclusions and Recommendations of TEEB; Progress Press: Birkirkara, Malta, 2010; ISBN 9783981341034.

5. Grêt-Regamey, A.; Brunner, S.H.; Kienast, F. Mountain Ecosystem Services: Who Cares? Mt. Res. Dev. 2012, 32, S23-S34. [CrossRef]

6. Bernués, A.; Rodríguez-Ortega, T.; Ripoll-Bosch, R.; Alfnes, F. Socio-cultural and economic valuation of ecosystem services provided by Mediterranean mountain agroecosystems. PLoS ONE 2014, 9, e102479. [CrossRef] [PubMed]

7. Millenium Ecosystem Assesment. Eccosystems and Human Well-Being: Synthesis; Island Press: Washington, DC, USA, 2005; ISBN 1-59726-040-1.

8. Sturaro, E.; Cocca, G.; Gallo, L.; Mrad, M.; Ramanzin, M. Sistemi zootecnici e stili aziendali sulle Alpi Orientali Italiane: Indagine su un campione di allevamenti. Ital. J. Anim. Sci. 2009, 8, 541-554. [CrossRef]

9. Mazzocchi, C.; Sali, G. Assessing the value of pastoral farming in the Alps using choice experiments: Evidence for public policies and management. J. Environ. Plan. Manag. 2019, 62, 552-567. [CrossRef]

10. Argenti, G.; Lombardi, G. The pasture-type approach for mountain pasture description and management. Ital. J. Agron. 2012, 7, 293-299. [CrossRef]

11. Baumont, R.; Prache, S.; Meuret, M.; Morand-Fehr, P. How forage characteristics influence behaviour and intake in small ruminants: A review. Livest. Prod. Sci. 2000, 64, 15-28. [CrossRef]

12. Poore, M.; Scaglia, G.; Andrae, J.; Harmon, D.; Rogers, J.; Blacklin, S. Pasture-Finished Beef Production in the South; Elsevier: Amsterdam, The Netherlands, 2019; ISBN 9780128144756.

13. Wilkinson, J.M.; Lee, M.R.F.; Rivero, M.J.; Chamberlain, A.T. Some challenges and opportunities for grazing dairy cows on temperate pastures. Grass Forage Sci. 2020, 75, 1-17. [CrossRef]

14. Tardella, F.M.; Bricca, A.; Goia, I.G.; Catorci, A. How mowing restores montane Mediterranean grasslands following cessation of traditional livestock grazing. Agric. Ecosyst. Environ. 2020, 295, 106880. [CrossRef]

15. Boscariol, G.P. La strategia per le aree interne quale strumento di sviluppo dei territori montani. Riv. Giuridica Mezzog. 2017, 3, 675-702.

16. Hinojosa, L.; Lambin, E.F.; Mzoughi, N.; Napoléone, C. Place attachment as a factor of mountain farming permanence: A survey in the French Southern Alps. Ecol. Econ. 2016, 130, 308-315. [CrossRef]

17. Hinojosa, L.; Napoléone, C.; Moulery, M.; Lambin, E.F. The "mountain effect" in the abandonment of grasslands: Insights from the French Southern Alps. Agric. Ecosyst. Environ. 2016, 221, 115-124. [CrossRef]

18. Lamprecht, A.; Semenchuk, P.R.; Steinbauer, K.; Winkler, M.; Pauli, H. Climate change leads to accelerated transformation of high-elevation vegetation in the central Alps. New Phytol. 2018, 220, 447-459. [CrossRef] [PubMed]

19. Gobiet, A.; Kotlarski, S.; Beniston, M.; Heinrich, G.; Rajczak, J.; Stoffel, M. 21st century climate change in the European Alps-A review. Sci. Total Environ. 2014, 493, 1138-1151. [CrossRef]

20. Heinrich, G.; Gobiet, A.; Truhetz, H.; Mendlik, T. Expected Climate Change and Its Uncertainty in the Alpine Region Extended Uncertainty Assessment of the Reclip: Century and ENSEMBLES Multi-Model Dataset; Scientific Report No. 50-2013; Wegener Center for Climate and Global Change: Graz, Austria, 2013.

21. Calanca, P. Climate change and drought occurrence in the Alpine region: How severe are becoming the extremes? Glob. Planet. Chang. 2007, 57, 151-160. [CrossRef]

22. Deléglise, C.; Meisser, M.; Mosimann, E.; Spiegelberger, T.; Signarbieux, C.; Jeangros, B.; Buttler, A. Drought-induced shifts in plants traits, yields and nutritive value under realistic grazing and mowing managements in a mountain grassland. Agric. Ecosyst. Environ. 2015, 213, 94-104. [CrossRef] 
23. Hock, R.; Rasul, G.; Adler, C.; Cáceres, B.; Gruber, S.; Hirabayashi, Y.; Jackson, M.; Kääb, A.; Kang, S.; Kutuzov, S.; et al. Chapter 2: High Mountain Areas. In IPCC Special Report on the Ocean and Cryosphere in a Changing Climate; Pörtner, H.-O., Roberts, D.C., Masson-Delmotte, V., Zhai, P., Tignor, M., Poloczanska, E., Mintenbeck, K., Alegría, A., Nicolai, M., Okem, A., et al., Eds.; Intergovernmental Panel on Climate Change (IPCC): Geneva, Switzerland, 2019; pp. 1-83.

24. Auer, I.; Böhm, R.; Jurkovic, A.; Lipa, W.; Orlik, A.; Potzmann, R.; Schöner, W.; Ungersböck, M.; Matulla, C.; Briffa, K.; et al. HISTALP-Historical instrumental climatological surface time series of the Greater Alpine Region. Int. J. Climatol. 2007, 27, 17-46. [CrossRef]

25. Gavazov, K.S.; Peringer, A.; Buttler, A.; Gillet, F.; Spiegelberger, T. Dynamics of forage production in pasture-woodlands of the Swiss Jura mountains under projected climate change scenarios. Ecol. Soc. 2013, 18, 38. [CrossRef]

26. Matteodo, M.; Wipf, S.; Stöckli, V.; Rixen, C.; Vittoz, P. Elevation gradient of successful plant traits for colonizing alpine summits under climate change. Environ. Res. Lett. 2013, 8, 024043. [CrossRef]

27. Pauli, H.; Gottfried, M.; Dullinger, S.; Abdaladze, O.; Akhalkatsi, M.; Alonso, J.L.B.; Coldea, G.; Dick, J.; Erschbamer, B.; Calzado, R.F.; et al. Recent Plant Diversity Changes on Europe's Mountain Summits. Science 2012, 336, 353-355. [CrossRef]

28. Carlson, B.Z.; Corona, M.C.; Dentant, C.; Bonet, R.; Thuiller, W.; Choler, P. Observed long-term greening of alpine vegetation-A case study in the French Alps. Environ. Res. Lett. 2017, 12, 114006. [CrossRef]

29. Schwager, P.; Berg, C. Global warming threatens conservation status of alpine EU habitat types in the European Eastern Alps. Reg. Environ. Chang. 2019, 19, 2411-2421. [CrossRef]

30. Hoegh-Guldberg, O.; Jacob, D.; Taylor, M.; Bindi, M.; Brown, S.; Camilloni, I.; Diedhiou, A.; Djalante, R.; Ebi, K.L.; Engelbrecht, F.; et al. Chapter 3: Impacts of $1.5^{\circ} \mathrm{C}$ global warming on natural and human systems. In Global Warming of $1.5^{\circ} \mathrm{C}$ : An IPCC Special Report; Intergovernmental Panel on Climate Change (IPCC): Geneva, Switzerland, 2018.

31. Dibari, C.; Bindi, M.; Moriondo, M.; Staglianò, N.; Targetti, S.; Argenti, G. Spatial data integration for the environmental characterization of pasture macrotypes in the Italian Alps. Grass Forage Sci. 2016, 71, $219-234$. [CrossRef]

32. Peel, M.C.; Finlayson, B.L.; McMahon, T.A. Updated world map of the Köppen-Geiger climate classification. Hydrol. Earth Syst. Sci. 2007, 11, 1633-1644. [CrossRef]

33. Schär, C.; Davies, T.D.; Frei, C.; Wanner, H.; Widmann, M.; Wild, M.; Davies, H.C. Current Alpine Climate; The MIT Press: Cambridge, MA, USA, 1998.

34. Beniston, M. Mountain weather and climate: A general overview and a focus on climatic change in the Alps. Hydrobiologia 2006, 562, 3-16. [CrossRef]

35. Baruck, J.; Nestroy, O.; Sartori, G.; Baize, D.; Traidl, R.; Vrščaj, B.; Bräm, E.; Gruber, F.E.; Heinrich, K.; Geitner, C. Soil classification and mapping in the Alps: The current state and future challenges. Geoderma 2016, 264, 312-331. [CrossRef]

36. Orlandi, S.; Probo, M.; Sitzia, T.; Trentanovi, G.; Garbarino, M.; Lombardi, G.; Lonati, M. Environmental and land use determinants of grassland patch diversity in the western and eastern Alps under agro-pastoral abandonment. Biodivers. Conserv. 2016, 25, 275-293. [CrossRef]

37. Lüth, C.; Tasser, E.; Niedrist, G.; Via, J.D.; Tappeiner, U. Plant communities of mountain grasslands in a broad cross-section of the Eastern Alps. Flora Morphol. Distrib. Funct. Ecol. Plants 2011, 206, 433-443. [CrossRef]

38. Argenti, G.; Bottai, L.; Chiesi, M.; Maselli, F.; Stagliano, N.; Targetti, S. Analysis and assessment of mountain pastures by integration of multispectral and ancillary data. Riv. Ital. Telerilevamento 2011, 43, 45-57. [CrossRef]

39. Breiman, L. Random Forests. Mach. Learn. 2001, 45, 5-32. [CrossRef]

40. Nachtergaele, F.; van Velthuizen, H.; Verelst, L. The Harmonized World Soil Database; Version 1.0.; FAO: Rome, Italy, 2008; pp. 34-37.

41. Hijmans, R.J.; Cameron, S.E.; Parra, J.L.; Jones, P.G.; Jarvis, A. Very high resolution interpolated climate surfaces for global land areas. Int. J. Climatol. 2005, 25, 1965-1978. [CrossRef]

42. Dibari, C.; Argenti, G.; Catolfi, F.; Moriondo, M.; Staglianò, N.; Bindi, M. Pastoral suitability driven by future climate change along the apennines. Ital. J. Agron. 2015, 10, 109-116. [CrossRef]

43. Ruti, P.M.; Somot, S.; Giorgi, F.; Dubois, C.; Flaounas, E.; Obermann, A.; Dell'Aquila, A.; Pisacane, G.; Harzallah, A.; Lombardi, E.; et al. Med-CORDEX initiative for Mediterranean climate studies. Bull. Am. Meteorol. Soc. 2016, 97, 1187-1208. [CrossRef] 
44. Targetti, S.; Staglianò, N.; Messeri, A.; Argenti, G. A state-and-transition approach to alpine grasslands under abandonment. IForest 2010, 3, 44-51. [CrossRef]

45. Cavallero, A.; Aceto, P.; Gorlier, A.; Lombardi, G.; Lonati, M.; Martinasso, B.; Tagliatori, C. I Tipi Pastorali delle Alpi Piemontesi; Alberto Perdisa Editore: Bologna, Italy, 2007.

46. Istituto Superiore per la Protezione e la Ricerca Ambientale. Il Progetto Carta della Natura: Linee Guida per la Cartografia e la Valutazione degli Habitat alla Scala 1:50.000; ISPRA: Rome, Italy, 2009; ISBN 9788844803810.

47. Bissardon, M.; Guibal, L. CORINE Biotopes: French Habitat Types [Typs d'Habitats Français]; École Nationale du Génie Rural, des Eaux et des Forêts: Nancy, France, 1997; p. 179.

48. Pignatti, S. Flora d'Italia; Edagricole: Bologna, Italy, 1982; ISBN 8850652429.

49. Raunkiaer, C. The Life Forms of Plants and Statistical Plant Geography; The Clarendon Press: Oxford, UK, 1934.

50. Attorre, F.; Alfò, M.; De Sanctis, M.; Francesconi, F.; Valenti, R.; Vitale, M.; Bruno, F. Evaluating the effects of climate change on tree species abundance and distribution in the Italian peninsula. Appl. Veg. Sci. 2011, 14, 242-255. [CrossRef]

51. Gaál, M.; Moriondo, M.; Bindi, M. Modelling the impact of climate change on the Hungarian wine regions using Random Forest. Appl. Ecol. Environ. Res. 2012, 10, 121-140. [CrossRef]

52. Moriondo, M.; Jones, G.V.; Bois, B.; Dibari, C.; Ferrise, R.; Trombi, G.; Bindi, M. Projected shifts of wine regions in response to climate change. Clim. Chang. 2013, 119, 825-839. [CrossRef]

53. Moriondo, M.; Trombi, G.; Ferrise, R.; Brandani, G.; Dibari, C.; Ammann, C.M.; Lippi, M.M.; Bindi, M. Olive trees as bio-indicators of climate evolution in the Mediterranean Basin. Glob. Ecol. Biogeogr. 2013, 22, 818-833. [CrossRef]

54. Cutler, D.R.; Edwards, T.C.; Beard, K.H.; Cutler, A.; Kyle, T.; Gibson, J.; Lawler, J.J.; Beard, H.; Hess, T. Random Forests for Classification in Ecology Published by: Ecological Society of America. Ecology 2007, 88, 2783-2792. [CrossRef]

55. Iverson, L.R.; Prasad, A.M.; Matthews, S.N.; Peters, M. Estimating potential habitat for 134 eastern US tree species under six climate scenarios. For. Ecol. Manag. 2008, 254, 390-406. [CrossRef]

56. Dibari, C.; Argenti, G.; Moriondo, M.; Staglianò, N.; Targetti, S.; Bindi, M. Climate change impacts on distribution and composition of the Alpine Natural Pasturelands. In Proceedings of the 1st Annual Conference Climate Change and Its Implications on Ecosystem and Society, Lecce, Italy, 23-24 September 2013; pp. 578-586.

57. Schroth, G.; Läderach, P.; Martinez-Valle, A.I.; Bunn, C.; Jassogne, L. Vulnerability to climate change of cocoa in West Africa: Patterns, opportunities and limits to adaptation. Sci. Total Environ. 2016, 556, $231-241$. [CrossRef] [PubMed]

58. Oshiro, T.M.; Perez, P.S.; Baranauskas, J.A. How Many Trees in a Random Forest? In Proceedings of the Lecture Notes in Computer Science; Perner, P., Ed.; Springer: Berlin/Heidelberg, Germany, 2012; pp. 154-168.

59. Allouche, O.; Tsoar, A.; Kadmon, R. Assessing the accuracy of species distribution models: Prevalence, kappa and the true skill statistic (TSS). J. Appl. Ecol. 2006, 43, 1223-1232. [CrossRef]

60. Harrison, M.T.; Cullen, B.R.; Rawnsley, R.P. Modelling the sensitivity of agricultural systems to climate change and extreme climatic events. Agric. Syst. 2016, 148, 135-148. [CrossRef]

61. Thornton, P.K.; Ericksen, P.J.; Herrero, M.; Challinor, A.J. Climate variability and vulnerability to climate change: A review. Glob. Chang. Biol. 2014, 20, 3313-3328. [CrossRef] [PubMed]

62. Scherrer, D.; Kãrner, C. Infra-red thermometry of alpine landscapes challenges climatic warming projections. Glob. Chang. Biol. 2010, 16, 2602-2613. [CrossRef]

63. Choler, P. Winter soil temperature dependence of alpine plant distribution: Implications for anticipating vegetation changes under a warming climate. Perspect. Plant Ecol. Evol. Syst. 2018, 30, 6-15. [CrossRef]

64. Cannone, N.; Sgorbati, S.; Guglielmin, M. Unexpected impacts of climate change on alpine vegetation. Front. Ecol. Environ. 2007, 7, 360-364. [CrossRef]

65. Unterluggauer, P.; Mallaun, M.; Erschbamer, B. The higher the summit, the higher the diversity changes-Results of a long-term monitoring project in the Dolomites. Gredleriana 2016, 16, 5-34.

66. Gehrig-Fasel, J.; Guisan, A.; Zimmermann, N.E. Tree line shifts in the Swiss Alps: Climate change or land abandonment? J. Veg. Sci. 2007, 18, 571-582. [CrossRef]

67. Motta, R.; Nola, P. Growth trends and dynamics in sub-alpine forest stands in the Varaita Valley (Piedmont, Italy) and their relationships with human activities and global change. J. Veg. Sci. 2001, 12, 219-230. [CrossRef] 
68. Chauchard, S.; Beilhe, F.; Denis, N.; Carcaillet, C. An increase in the upper tree-limit of silver fir (Abies alba Mill.) in the Alps since the mid-20th century: A land-use change phenomenon. For. Ecol. Manag. 2010, 259, 1406-1415. [CrossRef]

69. Rogora, M.; Frate, L.; Carranza, M.L.; Freppaz, M.; Stanisci, A.; Bertani, I.; Bottarin, R.; Brambilla, A.; Canullo, R.; Carbognani, M.; et al. Assessment of climate change effects on mountain ecosystems through a cross-site analysis in the Alps and Apennines. Sci. Total Environ. 2018, 624, 1429-1442. [CrossRef] [PubMed]

70. Klos, P.Z.; Link, T.E.; Abatzoglou, J.T. Extent of the rain-snow transition zone in the western U.S. under historic and projected climate. Geophys. Res. Lett. 2014, 41, 4560-4568. [CrossRef]

71. Petersky, R.S.; Shoemaker, K.T.; Weisberg, P.J.; Harpold, A.A. The sensitivity of snow ephemerality to warming climate across an arid to montane vegetation gradient. Ecohydrology 2019, 12, e2060. [CrossRef]

72. Ziliotto, U.; Andrich, O.; Lasen, C.; Ramanzin, M. Tratti Essenziali della Tipologia Veneta dei Pascoli di Monte e Dintorni; University of Padua: Padua, Italy, 2004; p. 253.

73. Güsewell, S.; Jewell, P.L.; Edwards, P.J. Effects of heterogeneous habitat use by cattle on nutrient availability and litter decomposition in soils of an Alpine pasture. Plant Soil 2005, 268, 135-149. [CrossRef]

74. Frate, L.; Carranza, M.L.; Evangelista, A.; Stinca, A.; Schaminée, J.H.J.; Stanisci, A. Climate and land use change impacts on mediterranean high-mountain vegetation in the apennines since the 1950s. Plant Ecol. Divers. 2018, 11, 85-96. [CrossRef]

75. Liu, Q.; Fu, Y.H.; Zhu, Z.; Liu, Y.; Liu, Z.; Huang, M.; Janssens, I.A.; Piao, S. Delayed autumn phenology in the Northern Hemisphere is related to change in both climate and spring phenology. Glob. Chang. Biol. 2016, 22, 3702-3711. [CrossRef]

76. Xu, C.; Liu, H.; Williams, A.P.; Yin, Y.; Wu, X. Trends toward an earlier peak of the growing season in Northern Hemisphere mid-latitudes. Glob. Chang. Biol. 2016, 22, 2852-2860. [CrossRef]

77. Park, T.; Chen, C.; Macias-Fauria, M.; Tømmervik, H.; Choi, S.; Winkler, A.; Bhatt, U.S.; Walker, D.A.; Piao, S.; Brovkin, V.; et al. Changes in timing of seasonal peak photosynthetic activity in northern ecosystems. Glob. Chang. Biol. 2019, 25, 2382-2395. [CrossRef]

78. Buitenwerf, R.; Rose, L.; Higgins, S.I. Three decades of multi-dimensional change in global leaf phenology. Nat. Clim. Chang. 2015, 5, 364-368. [CrossRef]

79. Gonsamo, A.; Chen, J.M.; Ooi, Y.W. Peak season plant activity shift towards spring is reflected by increasing carbon uptake by extratropical ecosystems. Glob. Chang. Biol. 2018, 24, 2117-2128. [CrossRef] [PubMed]

80. Pittarello, M.; Probo, M.; Perotti, E.; Lonati, M.; Lombardi, G.; Ravetto Enri, S. Grazing Management Plans improve pasture selection by cattle and forage quality in sub-alpine and alpine grasslands. J. Mt. Sci. 2019, 16, 2126-2135. [CrossRef]

81. Celaya, R.; Oliván, M.; Ferreira, L.M.M.; Martínez, A.; García, U.; Osoro, K. Comparison of grazing behaviour, dietary overlap and performance in non-lactating domestic ruminants grazing on marginal heathland areas. Livest. Sci. 2007, 106, 271-281. [CrossRef]

(C) 2020 by the authors. Licensee MDPI, Basel, Switzerland. This article is an open access article distributed under the terms and conditions of the Creative Commons Attribution (CC BY) license (http://creativecommons.org/licenses/by/4.0/). 